\title{
HIGHLIGHTING INTRACRANIAL PRESSURE MONITORING IN PATIENTS WITH SEVERE ACUTE BRAIN TRAUMA
}

\author{
ANTONIO L. E. FALCÃO*, IVENANCIO P. DANTAS FILHO*, LUIZA. C. SARDINHA*, ELIZABETHM. A. \\ B. QUAGLIATO**, DESANKA DRAGOSAVAC*, SEBASTIĀO ARAÚNO*, RENATO G. G. TERZI*
}

SUMMARY - Intracranial pressure (ICP) monitoring was carried out in 100 patients with severe acute brain trauma, primarily by means of a subarachnoid catheter. Statistical associations were evaluated between maximum ICP values and: 1) Glasgow Coma Scale (GCS) scores; 2) findings on computed tomography (CT) scans of the head; and 3) mortality. A significant association was found between low GCS scores (3 to 5) and high ICP levels, as well as between focal lesions on CT scans and elevated ICP. Mortality was significantly higher in patients with ICP $>40 \mathrm{~mm} \mathrm{Hg}$ than in those with ICP $\leq 20 \mathrm{~mm} \mathrm{Hg}$.

KEY WORDS: head injury, intracranial pressure, coma.

Ressaltando a monitorização da pressão intracraniana em pacientes com traumatismo cerebral agudo grave

RESUMO - Monitorização da pressão intracraniana (PIC) foi adotada em 100 pacientes com traumatismo cerebral agudo grave, usando-se preferencialmente um catéter subaracnóide. Associações estatísticas foram avaliadas entre valores máximos de PIC e : 1) número de pontos na Escala de Coma de Glasgow (ECG); 2) achados na tomografia computadorizada (TC) da cabeça; e 3) mortalidade. Encontrou-se associação significante entre baixo número de pontos ( 3 a 5) na ECG e PIC elevada, assim como entre lesões focais na TC e hipertensão intracraniana. A mortalidade foi significantemente maior em pacientes com $\mathrm{PIC}>40 \mathrm{~mm} \mathrm{Hg}$ do que naqueles com PIC $\leq 20 \mathrm{~mm} \mathrm{Hg}$.

PALAVRAS-CHAVE: traumatismo cerebral, pressão intracraniana, coma.

Continuous monitoring of intracranial pressure (ICP) in humans was first proposed by Guillaume and Janny ${ }^{10}$. This landmark contribution was followed by extensive work of Lundberg on the same subject ${ }^{11}$, where ICP patterns were more thoroughly established. Post-traumatic intracranial hypertension has been associated with increased morbidity and mortality ${ }^{12-14}$. When elevated ICP occurs, cerebral blood flow may decrease? ${ }^{7}$. Conversely, increases in cerebral blood flow (cerebral luxury perfusion) may also significantly contribute to relevant ICP increments ${ }^{45,17}$. In addition to cerebral hemodynamic changes, brain edema may also play a role in the pathophysiology of intracranial hypertension ${ }^{6.9}$.

Routine ICP monitoring has been adopted at our institution since 1989. Over the years, our preference has been for subarachnoid catheter monitoring. This technique appears to satisfactorily comply with clinical requirements, particularly because it is practical, inexpensive, and carries just a small risk of complications. The present work is an outgrowth of our experience. Attempts were

Intensive Care Unit" and Department of Neurology"*, Hospital das Clinicas, Universidade Estadual de Campinas (UNICAMP), São Paulo. Aceite: 22-fevereiro-1995.

Dr. Antonio L. E. Falcão - Rua Dr. Lauro Pimentel 195 - Cidade Universitária, UNICAMP - 13083-250 Campinas SP - Brasil. 
made to delineate statistical associations between elevated ICP and other parameters related to the diagnosis and management of severe acute brain trauma.

\section{CLINICAL MATERIAL AND METHODS}

During the period from June 1989 to April 1992, one hundred patients were prospectively evaluated in our Intensive Care Unit (ICU). Age ranged from 11 to 70 years, with $81 \%$ of the patients in the range of 11 to 40 years. There were 81 males and 19 females. All patients were comatose, with Glasgow Coma Scale ${ }^{20}$ (GCS) scores of 8 or less on admission to the ICU. Automobile accidents represented the most frequent cause of injury (54\%), followed by motorcycle accidents (17\%) and other causes $(29 \%)$.

All patients underwent mechanical ventilation and ICP monitoring. The latter was by means of a subarachnoid catheter in 89 of the patients, or a subarachnoid bolt in the remaining 11. Placement of the ICP monitor was in the ICU, at bedside, in most patients. Only if acute surgical lesions were diagnosed, ICP monitors were placed in the operating room, immediately after intracranial surgery. The catheter was filled with a cephalosporin. As to complications of this technique, only one patient (1\%) developed cerebrospinal fluid infection which responded to therapy.

For classification purposes, ICP was considered normal if $\leq 10 \mathrm{~mm} \mathrm{Hg}$, mildly elevated if from 11 to 20 $\mathrm{mm} \mathrm{Hg}$, moderately elevated if from 21 to $40 \mathrm{~mm} \mathrm{Hg}$, and markedly elevated if $>40 \mathrm{~mm} \mathrm{Hg}$. Intracranial hypertension was managed according to a cumulative protocol to maintain ICP below $20 \mathrm{~mm} \mathrm{Hg}^{2}$. According to Cruz protocol, in addition to therapeutic ICP normalization, we have also recently attempted to maintain normalized cerebral extraction of oxygen $\left(\mathrm{CEO}_{2}\right)^{\text {2-5 }}$ (arteriojugular oxyhemoglobin saturation difference). This additional management modality is because $\mathrm{CEO}_{2}$ normalization represents adequate therapeutic match between global cerebral consumption of oxygen and cerebral blood flow ${ }^{3-5}$.

Statistical associations were evaluated between ICP and : 1) GCS scores on admission to the ICU; 2) predominant findings on the admission computed tomography (CT) scan of the head; and 3) mortality. Statistically assessed ICP values were the highest documented throughout the acute phase. Chi-squared test (with Yates' correction if necessary) was usèd for statistical evaluation, and a $p$ value $<0.05$ was considered significant.

\section{RESULTS}

There was a significant association between low GCS scores ( 3 to 5) and severe intracranial hypertension (Table 1). Likewise, there was a significant association between predominantly focal

Table I. Intracranial pressure versus coma scores.

\begin{tabular}{ccccc}
\hline & & \multicolumn{3}{c}{ ICP } \\
\cline { 2 - 5 } GCS & $\leqslant 20$ & $21-40$ & $>40$ & Total \\
\hline $3-5$ & 14 & 12 & 24 & 50 \\
$6-8$ & 20 & 18 & 12 & 50 \\
Total & 34 & 30 & 36 & 100 \\
\hline
\end{tabular}

Distribution of the patients according to admission Glasgow Coma Scale (GCS) scores and maximum levels of intracranial pressure (ICP, in mm $\mathrm{Hg}$ ). A significant difference was found ( $p<0.05$, chis-squared test).

Table 2. Intracranial pressure versus major CT findings.

\begin{tabular}{ccccc}
\hline & \multicolumn{3}{c}{ ICP } \\
\cline { 2 - 5 } Major CT findings & $\leqslant 20$ & $21-40$ & $>40$ & Total \\
\hline Focal & 22 & 25 & 32 & 79 \\
Diffuse & 12 & 5 & 4 & 21 \\
Total & 34 & 30 & 36 & 100 \\
\hline
\end{tabular}

Distribution of the patients according to major findings on the admission computed tomography (CT) scans of the head and maximum levels of intracranial pressure (ICP, in $\mathrm{mm} \mathrm{Hg}$ ). A significant difference was found . ( $p<0.04$, chi-squared test). 
CT findings and markedly elevated ICP (Table 2). A significant association was also found between mortality and severe intracranial hypertension (Table 3).

Table 3. Intracranial pressure versus outcome.

\begin{tabular}{ccccc}
\hline & & \multicolumn{3}{c}{ ICP } \\
\cline { 2 - 5 } Outcome & $\leqslant 20$ & $21-40$ & $>40$ & Total \\
\hline Survival & 30 & 22 & 10 & 62 \\
Death & 4 & 8 & 26 & 38 \\
Total & 34 & 30 & 36 & 100 \\
\hline
\end{tabular}

Distribution of the patients according to two major outcome categories and maximum levels of intracranial pressure (ICP, in $\mathrm{mm} \mathrm{Hg}$ ). A significant difference was found ( $\mathrm{p}<0.002$, chi-squared test).

\section{DISCUSSION}

\section{ICP monitoring}

Intracranial pressure monitoring in patients with acute traumatic coma has been advocated under a variety of circumstances. While Miller has previously proposed ICP monitoring in all comatose patients with acute brain injuries ${ }^{15}$, Cruz has recently reported ICP and $\mathrm{CEO}_{2}$ monitoring in selected patients only, in whom the cerebrospinal fluid spaces were compromised. This excluded patients with normal CT findings, and those with pure diffuse axonal injury (without associated brain swelling)s.

ICP monitoring has also been addressed as a means of monitoring cerebral perfusion pressure (the difference between mean arterial pressure and intracranial pressure). In fact, this monitoring capability has been advocated as a guide for management of cerebral perfusion pressure, besides ICP $14,15.18$.

Conversely, management of severely brain-injured patients has also been reported without ICP monitoring ${ }^{19}$. In this single report by Stuart and co-workers, the overall mortality rate was $34 \%$. However, a comparative group of patients undergoing aggressive ICP monitoring and management was not evaluated, so that mortality rates were not thoroughly compared.

As to the monitoring technique, indications, limitations, and complications of different technical modalities have been previously addressed ${ }^{18,16.21}$. Mollman and co-workers ${ }^{16}$ conducted a comparative study on ICP monitoring with a ventricular catheter, a subarachnoid catheter, and a subarachnoid bolt. In this study ${ }^{16}$, monitoring with a subarachnoid bolt tended to underestimate ICP increases, while no significant differences were found between ventricular and subarachnoid catheter monitoring. These findings add support to our routine adoption of subarachnoid catheter monitoring in most patients.

\section{GCS scores and ICP}

Our results disclosed a significant association between low GCS scores and markedly elevated ICP. These findings are in agreement with those of Yano and co-workers ${ }^{21}$. Whether elevated ICP contributed to neurologic impairment (low GCS scores) is not clear. In fact, according to our findings and those of others ${ }^{21}$, just associations were found. The latter, however, do not necessarily indicate cause-and-effect relationships.

\section{CT findings and ICP}

Our data revealed a tendency for patients with focal CT findings to have more pronounced ICP problems. This involved post-operative ICP recordings, and those in patients with non-surgical hemorrhagic contusions as well. It should be emphasized, however, that severe ICP problems may 
also be found in patients with predominantly diffuse brain swelling ${ }^{4}$. Thus, our results do not rule out the relevance of ICP monitoring in patients with predominantly diffuse traumatic brain swelling; rather, they highlight the importance of ICP monitoring even in patients in whom acute intracranial hematomas have been emergently removed.

\section{Mortality and ICP}

Our findings of increased mortality in patients who developed markedly elevated ICP are in agreement with previous reports ${ }^{12,13,21}$. Yano and co-workers ${ }^{21}$ have previously found a mortality rate of $93.4 \%$ in patients with ICP levels $>40 \mathrm{~mm} \mathrm{Hg}$ (versus $72.2 \%$ in our series). These impressive figures have been found despite relatively sophisticated standards for intensive care and monitoring, and argue for additional research efforts on novel therapeutic modalities for adequate control of markedly elevated ICP in these critically ill patients.

\section{CONCLUSIONS}

From the above described, it is apparent that routine ICP monitoring in severely brain-injured patients should be taken into account, particularly in cases with CT scan evidence of compromised cerebrospinal fluid spaces. This would involve patients without surgical lesions, as well as selected cases in whom acute intracranial hematomas have been emergently removed.

Acknowledgment - The authors thank Julio Cruz, M.D.,Ph.D., for critically reviewing and editing the manuscript.

\section{REFERENCES}

1. Colli BO, Falcão ALE, Dantas VP Filho. [Intracranial hypertension - monitoring and treatment]. In Terzi RGG, Araújo S (eds). Técnicas Básicas em UTI. São Paulo: Manole, 1992, p $401-417$ (Port).

2. Cruz J. On-line monitoring of global cerebral hypoxia in acute brain injury: relationship to intracranial hypertension. J Neurosurg 1993, 79:228-233.

3. Cruz J, Jaggi JL, Hoffstad OJ. Cerebral blood flow and oxygen consumption in acute brain injury with acute anemia: An alternative for the cerebral metabolic rate of oxygen consumption? Crit Care Med 1993, 21:1218-1224.

4. Cruz J. Combined continuous monitoring of systemic and cerebral oxygenation in acute brain injury: Preliminary observations. Crit Care Med 1993, 21:1225-1232.

5. Cruz $J$. An additional therapeutic effect of adequate hyperventilation in severe acute brain trauma: normalization of cerebral glucose uptake. J Neurosurg 1995, 82:379-385.

6. Dearden NM. Brain edema and raised intracranial pressure after head injury. In Vincent JL (ed). Yearbook of intensive care and emergency medicine. Berlin: Springer-Verlag, 1992, p 537-552.

7. Dickman CA, Carter P, Baldwin HZ, Harrington T, Tallman D. Continuous regional cerebral blood flow monitoring in acute craniocerebral trauma. Neurosurgery 1991, 28:467-472.

8. Falcão ALE, Dantas VP Filho, Saraiva JFK, Sardinha LAC, Araújo S, Terzi RGG. Bedside ICP monitoring in head trauma patients by using a simple, safe and low cost methodology (Abstr). Clin Int Care 1992, (Suppl) 3:112.

9. Fishman RA. Brain edema. N Engl J Med 1975, 393:706-711.

10. Guillaume J, Janny P. Manometrie intracrânienne continue: intérêt de la méthode et premiers résultats. Rev Neurol 1951, 84:131-142.

11. Lundberg N. Continuous recording and control of ventricular fluid pressure in neurosurgical practice. Acta Psychiatr Neurol Scand 1960, (Suppl 149) 36:1-193.

12. Marmarou A, Anderson RL, Ward JD, Choi SC, Young HF, Eisenberg HM, Foulkes MA, Marshall LF, Jane JA. Impact of ICP instability and hypotension on outcome in patients with severe head trauma. $J$ Neurosurg 1991, (Suppl) 75:S59-S66.

13. Marshall LF, Smith RW, Shapiro HM. The outcome with aggressive treatment in severe head injuries. Part 1: The significance of intracranial pressure monitoring. J Neurosurg 1979, 50:20-25.

14. McGillicuddy JE. Cerebral protection, pathophysiology and treatment of increased intracranial pressure. Chest $1985,87: 85-93$.

15. Miller JD. ICP monitoring: current status and future directions. Acta Neurochir 1987, 85:80-86. 
16. Mollman HD, Rockswold GL, Ford SE. A clinical comparison of subarachnoid catheters to ventriculostomy and subarachnoid bolts: a prospective study. J Neurosurg 1988, 68:737-741.

17. Obrist WD, Langfitt TW, Jaggi JL, Cruz J, Gennarelli TA. Cerebral blood flow and metabolism in comatose patients with acute head injury: relationship to intracranial hypertension. J Neurosurg 1984, 61:241-253.

18. Rosner MJ, Daughton S. Cerebral perfusion pressure management in head injury. J Trauma 1990, 30:933-941.

19. Stuart GG, Merry GS, Smith JA, Yelland DN. Severe head injury managed without intracranial pressure monitoring. J Neurosurg 1983, 59:601-605.

20. Teasdale G, Jennett B. Assessment of coma and impaired consciousness: a practical scale. Lancet 1974, 2:81-84.

21. Yano M, Kobayashi S, Otsuka T. Useful ICP monitoring with subarachnoid catheter method in severe head injuries. J Trauma 1988, 28:476-480. 